\title{
EL NUEVO TRATAMIENTO DEL RÉGIMEN DE LA CAPACIDAD EN EL CÓDIGO CIVIL PERUANO
}

\author{
Enrique Varsi-Rospigliosi ${ }^{1}$, Marco Andrei Torres Maldonado ${ }^{2}$
}

Resumen: El Perú cuenta con un nuevo tratamiento de la capacidad en el Código Civil de 1984, logrando un acercamiento a las directrices de las Naciones Unidas en pro de la autonomía y la plena capacidad jurídica de las personas con discapacidad. Mediante las últimas modificaciones, realizadas por el Decreto Legislativo No 1384, se unen varios aspectos inconclusos en torno a los derechos de las personas con discapacidad, sobre la base del respeto a los derechos humanos de todos los ciudadanos, especialmente en cuanto a su dignidad, autonomía e igualdad ante la ley. El modelo social vigente remplaza el régimen de sustitución de la voluntad de las personas incapaces, por uno de asistencia a través de los denominados apoyos y salvaguardias. Toda persona, independientemente de su capacidad, es un sujeto de derecho libre de tomar y responder de sus decisiones personales.

Palabras clave: capacidad, discapacidad, incapacidad, Convención sobre los derechos de las personas con discapacidad, apoyo, salvaguardia

\section{The new treatment of the capacity regime in the Peruvian Civil Code}

\begin{abstract}
Peru has a new capacity treatment in the Civil Code of 1984, achieving an approach to the guidelines of the United Nations in favor of the autonomy and full legal capacity of persons with disabilities. Through the latest modifications made by Legislative Decree N. 1384, several unfinished aspects are linked to the rights of persons with disabilities based on respect for the human rights of all citizens, especially in terms of their dignity, autonomy and equality before the law. The current social model replaces the regime of substitution of the will of the incapable by one of assistance through the so-called supports and safeguards. Every person, regardless of their capacity, is a subject of free right to take and respond to their personal decisions.
\end{abstract}

Keywords: capacity, disability, disability, Convention on the Rights of Persons with Disabilities, support, safeguarding

\section{E novo tratamento do regime da capacidade no Código Civil peruano}

Resumo: O Peru conta com um novo tratamento da capacidade no Código Cicil de 1984, alcançando acercar-se das diretrizes das Naçốes Unidas em prol da autonomia e da plena capacidade jurídica das pessoas com incapacidade. Mediante as últimas modificaçóes realizadas pelo Decreto Legislativo No 1384, unem-se vários aspectos inacabados em torno dos direitos das pessoas com incapacidade sobre uma base de respeito aos direitos humanos de todos os cidadáos, especialmente quanto a sua dignidade, autonomia e igualdade perante a lei. $\mathrm{O}$ modelo social vigente troca o regime de substituição da vontade das pessoas incapazes por um de assistência através dos denominados apoios e salvaguardas. Toda pessoa, independentemente de sua capacidade, é um sujeito de direito livre para tomar e responder por suas decisóes pessoais.

Palavras chave: capacidade, deficiência, incapacidade, Convenção sobre os direitos das pessoas com deficiência, apoio, salvaguarda

\footnotetext{
${ }^{1}$ Facultad de Derecho de la Universidad de Lima. CONCYTEC, Perú Correspondencia: enriquevarsi@gmail.com

${ }^{2}$ Universidad Nacional Mayor de San Marcos. Universidad de Lima, Perú
} 


\section{Introducción}

A través de la última reforma efectuada al Código Civil, mediante el Decreto Legislativo No 1384 (DOEP., 04/09/18), se deja de lado el tratamiento paternalista a las personas con discapacidad y estas pasan a ser parte de un régimen de igualdad jurídica. Ello ha permitido que el ordenamiento jurídico peruano se acerque a las directrices de las Naciones Unidas, lo que implica el respeto a los derechos humanos de todos los ciudadanos, especialmente en cuanto a su dignidad, autonomía e igualdad ante la ley.

En el Perú, previo al efectivo reconocimiento de la autodeterminación de las personas discapacitadas, se recurría a la interdicción y a la posterior designación de un curador para que pudieran realizar negocios jurídicos válidos. La curatela, como sistema de sustitución de voluntad, presentaba un serio obstáculo para la integración a la vida comunitaria de las personas con discapacidad, además de impedir su realización personal.

De tal manera, la reforma efectuada al Código Civil, cuyas principales modificaciones analizaremos a continuación, finalmente logra unir los cabos sueltos en la legislación peruana en torno — principalmente- al artículo 12 de la Convención sobre los Derechos de las personas con discapacidad $^{3}$ (en adelante, la Convención), que regula la autonomía y capacidad jurídica de las personas con discapacidad.

\section{Conceptos necesarios}

Debemos de tener presente que la nueva regulación de las personas con discapacidad, introducida por el Decreto Legislativo No 1384, es extensa e importante. No solo ha significado la modificación de disposiciones en los Libros de Personas,

\footnotetext{
${ }^{3}$ Aprobada por la Asamblea General de las Naciones Unidas en su Sexagésimo primer periodo de sesiones, mediante Resolución NRES/61/106, del 13 de diciembre de 2006, aprobada por el Congreso de la República mediante Resolución Legislativa № 29127 de fecha 30 de Octubre del 2007, publicado en el diario oficial $E l$ Peruano el 01 de noviembre de 2007 y ratificada por el presidente de la República, según Decreto Supremo N 073-2007-RE, de fecha 30 de diciembre de 2007, publicado en el diario oficial El Peruano el 31 de diciembre de 2007. Tiene como propósito máximo el promover, proteger y asegurar el goce pleno y en condiciones de igualdad de todos los derechos humanos y libertades fundamentales por todas las personas con discapacidad, y fomentar el respeto de su dignidad inherente.
}

Acto Jurídico, Familia, Sucesiones, Reales, Contratos y derogaciones en Fuente de las Obligaciones sino que, además, ha obligado al operador jurídico a reconceptualizar algunas instituciones del ordenamiento y a conocer otras nuevas.

Sin embargo, a lo largo del presente trabajo también podremos dar a conocer los desfases teóricos que ha traído consigo la nueva regulación y los efectos - y problemas - prácticos que no ha podido evitar.

A efectos de mantener una uniformidad conceptual y armonía con la nueva legislación, expondremos los conceptos de "capacidad", "incapacidad" y "discapacidad”, además de las nuevas instituciones que trae consigo la Convención, esto es, el apoyo y las salvaguardias.

\subsection{Capacidad}

La capacidad es un atributo que tiene toda persona natural, mediante el cual el sujeto puede realizar actos que no estén prohibidos. Es, por un lado, una aptitud para ser titular de relaciones(1:116) y, por otro, es un concepto núcleo del Derecho(2:105). De igual manera, en otra sede, hemos referido que la capacidad es, en una acepción amplia, una aptitud: se es capaz en la medida que se puede realizar algo(3:803).

En la misma sintonía lo ha definido el profesor Espinoza Espinoza, en tanto entiende a la capacidad que se expresa en dos estados: un estado estático que se manifiesta a través de la capacidad de goce. Y un estado dinámico que se manifiesta a través de la capacidad de ejercicio(4:871).

La capacidad, acorde a la doctrina más aceptada, se clasifica en capacidad de goce y capacidad de ejercicio.

\subsubsection{Capacidad de goce}

La capacidad de goce es el efecto del reconocimiento del Derecho de la existencia de condiciones por las que un ser es idóneo de tener intereses dignos de tutela(3:821).

Los sujetos de derecho presentan de manera inmanente capacidad de goce, que se presenta como la aptitud para ser titulares de relaciones jurídi- 
cas(4:722). Como tal, no puede ser restringida, solo puede restringirse la capacidad de ejercicio, limitándose en determinados casos, los cuales se dictan en consonancia con el principio de legalidad.

Con relación a ello, el profesor Fernández Sessarego ha criticado la antigua redacción del Código Civil, pues en su artículo 3 se precisaba que la capacidad de goce podría ser limitada por ley, cuando esto no puede concebirse de esa manera, pues la capacidad de goce es inherente al ser humano.

La tradición en cierta parte de la academia peruana entendió a la capacidad de goce como a la capacidad jurídica; sin embargo, y sobre todo a raíz de la Convención, esta se ha ampliado y ahora subsume tanto a la capacidad de goce como a la capacidad de ejercicio. Esto servirá para poder explicar, de manera más detallada, las modificaciones de las que ha sido materia nuestro Código Civil.

\subsubsection{Capacidad de ejercicio}

Para Marcial Rubio, "la capacidad de ejercicio es la atribución de la persona de ejecutar por sí misma los derechos a los que tiene capacidad de goce" (5:150).

Esta capacidad es la que le permite realizar deberes y derechos a través de actos jurídicos. En comparación con la capacidad de goce, esta puede ser limitada a través de leyes, sujetas a ciertos criterios. A pesar de lo dicho, se entiende en la actualidad que la capacidad de ejercicio, en conjunción con la capacidad de goce, son plenas en cada persona y solo serán restringidas cuando mande la ley.

\subsubsection{Incapacidad absoluta y relativa. Capacidad plena y restringida}

La capacidad, incapacidad absoluta o incapacidad relativa, de manera precedente a la reforma mediante del Decreto Legislativo No 1384, era la manera como se regulaba la capacidad en nuestro Código Civil. La validez de los actos jurídicos se basaba, principalmente, en el discernimiento y otros caracteres, como el etario. Los actos jurídicos de los incapaces absolutos se calificaban como nulos y los de los incapaces relativos como anulables, según los artículos 219 y 221, respectivamente, del Código Civil.

El nuevo sistema de capacidad suprime el sistema de sustitución, que primaba para los privados de discernimiento y demás personas con discapacidades, a fin de que pudieran ejercer sus derechos y deberes de manera válida a través de su curador. Siendo así, ahora estos individuos cuentan con capacidad jurídica plena, lo cual, de manera principal, les permite autodeterminarse en función a su autonomía y dignidad.

Ahora se considera incapaces absolutos solo a los menores de dieciséis años, salvo para aquellos actos determinados por ley (artículo 43) y sujetos con capacidad restringida a los siguientes:

- Los mayores de dieciséis y menores de dieciocho años.

- Los pródigos.

- Los que incurren en mala gestión.

- Los ebrios habituales.

- Los toxicómanos.

- Los que sufren pena que lleva anexa la interdicción civil.

- Las personas que se encuentran en estado de coma, siempre que no hubieran designado un apoyo con anterioridad.

\subsection{Discapacidad}

El concepto de "discapacidad" no ha sido estático a través del tiempo. En la década de 1980, la Organización Mundial de la Salud (en adelante, OMS) manejaba un concepto enfocado principalmente a la enfermedad y la dificultad que esta representa para que se desenvuelva el individuo. Presentaba tres conceptualizaciones distintas y autónomas que se relacionaban con aspectos diferentes de la experiencia que constituye enfermedad: deficiencia, discapacidad y minusvalía(6:129-138):

- Deficiencia, es la exteriorización de un estado patológico, que es consecuencia de alguna causa. Es un ámbito estrictamente médico. 
- Discapacidad, es la consecuencia de la deficiencia en la alteración funcional que tiene la persona en aspectos esenciales de su vida diaria, cotidiana.

- Minusvalía, es la socialización de una deficiencia o capacidad, i.e. la discrepancia del accionar del sujeto y las expectativas de la sociedad.

Conforme lo descrito, citamos a Lourdes Aparicio(6:129-138), estudiosa de la conceptualización de la discapacidad:

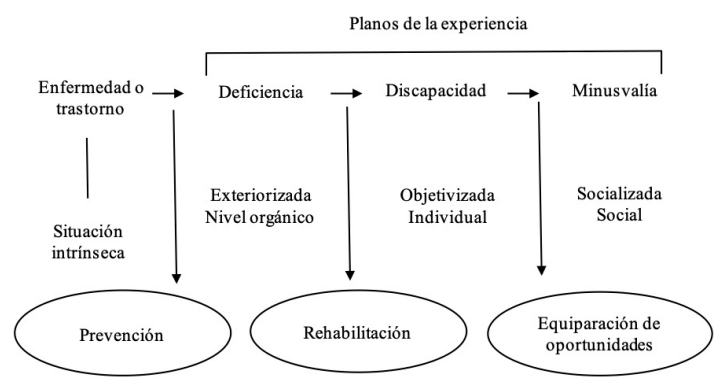

Figura 1: La enfermedad y sus consecuencias: Deficiencia, Discapacidad y Minusvalia (OMS, 1980).

No obstante, en 2001, en lugar de realizar una clasificación de la discapacidad centrada en las limitaciones como fue realizada anteriormente, la OMS redirigió el enfoque a los aspectos positivos de las misma, a los factores sanos (posibilidades), en vez de a la discapacidad (aspecto negativo). Esta es la llamada "clasificación internacional del funcionamiento de la discapacidad y la salud" (en adelante, CIF).

De tal modo, se cambian los tres conceptos antes mencionados, a los de deficiencia, actividad y participación, además de la inclusión de los factores del contexto.

Deficiencia: se refiere al aspecto estático de la persona, en relación con la deficiencia a nivel orgánico que presenta.

Actividad: se enfoca en las actividades de la vida diaria que puede desempeñar el individuo.

Participación: mide el nivel de funcionamiento en sociedad del sujeto y su participación activa.

Los factores del contexto se presentan como ambientales y personales, los cuales se manifiestan como las actitudes del mundo social y las medidas de accesibilidad, facilitadoras, que pueda otorgar el mundo físico.

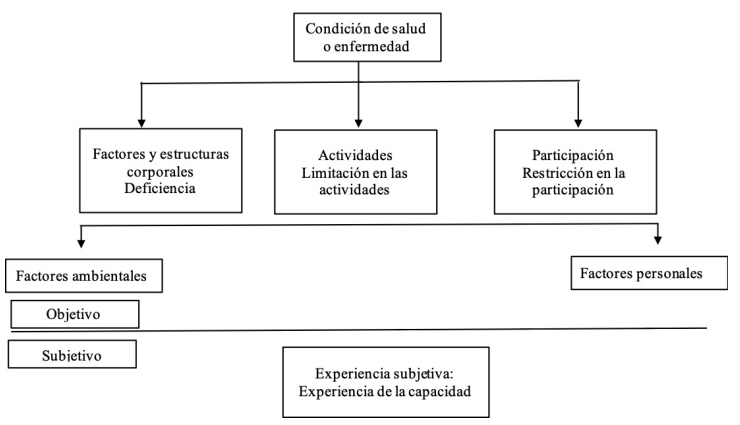

Figura $\mathrm{N}^{\circ}$ 2: Componentes del proceso de disca$\operatorname{pacidad}(7: 32)$.

Para Satoshi Ueda, la discapacidad es el resultado de la interacción entre una persona que tiene una determinada condición de salud y el contexto ambiental en que se desenvuelve. No tiene un carácter estático, sino que puede variar (aumentar o disminuir) con los cambios del entorno.

Resulta de importancia hacer mención a esta clasificación conceptual realizada por la OMS, en atención a los criterios considerados en la Convención, a efectos de interpretar el estado de la persona con discapacidad a través del tiempo. Así, se ha entendido que el sujeto con discapacidad ha pasado de un modelo de prescindencia, transcurrido por un modelo rehabilitador $y$, finalmente, ha llegado a un modelo denominado "social" (8:25).

\section{a. Modelo de prescindencia}

Bajo este modelo, la discapacidad se persigue como un castigo de origen divino y quien la padezca es considerado como una carga social innecesaria. La exposición de motivos del Anteproyecto de Ley que propone modificar el Decreto Legislativo 295 del Código Civil, en lo referido al ejercicio de la capacidad jurídica, refiere que, en el Perú, un caso que se subsume en este modelo es el de abandono de personas con discapacidad 
mental en institutos de salud mental.

\section{b. Modelo rehabilitador}

En este modelo, ya no se ve a la persona con discapacidad como algo de lo que debe prescindirse, sino como personas que deben volver a formar parte de la sociedad mediante un proceso de rehabilitación o readaptación. Es este modelo el que interpreta que las personas con discapacidad requieren de la sustitución en la toma de sus decisiones, toda vez que suponía una disminución o ausencia de su capacidad.

\section{c. Modelo social}

Este modelo es el que corresponde a la Convención y explica a la discapacidad como el estado de una persona con deficiencias físicas, sensoriales, intelectuales o mentales, pero que es la propia sociedad la que, por su propia estructura, crea barrearas para su desarrollo.

En tal sentido, lo que se busca es eliminar esas barreras, jurídicas y sociales, con la finalidad de que la persona con discapacidad pueda desenvolverse según sus funcionalidades especiales, teniendo como centro y eje los valores vida humana y dignidad. En consecuencia, el ordenamiento, al no reconocerle capacidad, no coadyuva a esta finalidad, por lo que la Convención precisó la necesidad de un cambio en el paradigma legislativo.

\subsection{Retraso mental}

El concepto de "retraso mental" reviste una importancia en nuestro sistema legal. La relación de la válida manifestación de la voluntad y el discernimiento ha sido muy estrecha.

De manera previa a la reforma se consideraba que "los que por cualquier causa se encuentren privados de discernimiento" eran incapaces absolutos; y que "los retardados mentales" y "los que adolecen de deterioro mental que les impide expresar su libre voluntad" eran incapaces relativos.

Así como la definición de "discapacidad" no se ha mantenido firme en el tiempo y ha ido evolucionando, la de "retraso mental" también ha evidenciado cambios. La Asociación Americana sobre Retraso Mental, en 2002, elaboró la siguiente definición de retraso mental:

"Retraso mental es una discapacidad caracterizada por limitaciones significativas en el funcionamiento intelectual y la conducta adaptativa, tal como se ha manifestado en habilidades prácticas, sociales y conceptuales. Esta discapacidad comienza antes de los 18 ańos"(9:6).

Es necesario agregar que el retraso mental no es una característica del individuo, ni un trastorno médico o mental. Es un estado concreto de funcionamiento que comienza en la infancia, es multidimensional y está afectado positivamente por apoyos individualizados(7:314-315). Por lo cual, con el ambiente y apoyos necesarios, una persona con retraso mental puede desenvolverse y expresar libremente su voluntad.

Para entender lo que representa la reforma en este ámbito, es necesario deslindar dos conceptos: la capacidad jurídica y la capacidad mental.

La capacidad jurídica es la capacidad de ser titular de derechos y obligaciones y de ejercer los mismos (legitimación para actuar).

La capacidad mental (natural) se refiere a la aptitud para adoptar decisiones; es variable y depende del individuo en cuestión, en función a diversos factores como los ambientales y sociales.

Siendo así, el artículo 12 de la Convención no permite negar la capacidad jurídica a los individuos con cualquier tipo de discapacidad. Efectuar dicha negación es una discriminación arbitraria que atenta contra la igualdad de condiciones de las personas con habilidades especiales dentro de la sociedad.

\subsection{Sistemas de apoyo}

En la Convención no se especifica de manera clara lo que son los apoyos. En el artículo 12, inciso 3 , solo se establece que:

"Los Estados Partes adoptarán las medidas pertinentes para proporcionar acceso a las personas con discapacidad al apoyo que puedan necesitar en el ejercicio de su capacidad jurídica”.

Sin embargo, el Comité, en la Observación gene- 
ral sobre el artículo 12, señala que: "Apoyo es un término amplio que engloba arreglos oficiales y oficiosos, de distintos tipos e intensidades". Ante un sistema excesivamente paternalista, como lo era el sistema de interdictos, surge un sistema acorde al modelo social: el sistema de apoyos. Este sistema no se da como la búsqueda de un sustituto a la voluntad de la persona discapacitada, sino como una herramienta para asegurar el efectivo ejercicio de su capacidad jurídica(10:55).

Estas medidas pueden ser relacionadas a escoger cuántas personas de apoyo necesitan en su vida diaria, quiénes serán y rechazar a las que no desean. Asimismo, comprende la asistencia para comunicarse y accesibilidad universal (como el ofrecimiento de las entidades de información comprensible, en lenguaje sencillo) o el reconocimiento de medios de comunicación no convencionales (para las personas que usan formas de comunicación no verbales).

La finalidad es que las personas con discapacidad puedan ejercer de manera autónoma su capacidad jurídica y celebrar actos jurídicos válidos, sin que el Estado deba sustituir su voluntad por la de un tercero. Finalmente, cabe resaltar que las personas discapacitadas también pueden rechazar el apoyo pues, como lo veremos más adelante, su designación, en nuestro ordenamiento, es potestativa, no imperativa.

\subsection{Salvaguardias}

Debido a que en un número considerable de casos los representantes de las personas con habilidades especiales no actuaban en el interés de su representado e incluso abusaban de su poder, se creó la figura de la salvaguarda ${ }^{4}$.

El Comité indica que "El objetivo principal de esas salvaguardias debe ser garantizar el respeto de los derechos, la voluntad y las preferencias de la persona. Para lograrlo, las salvaguardias deben proporcionar protección contra los abusos en igualdad de condiciones con las demás personas"s. Siendo así, la salvaguardia reemplaza el "principio

\footnotetext{
${ }^{4}$ Instituto de Democracia y Derechos Humanos (2015) p. 216.

${ }^{5}$ Organización de las Naciones Unidas, Comité sobre los derechos de las personas con discapacidad, GE.13-49146 (30 de marzo al 11 de abril de 2014).
}

de mejor interés» que se identificaba con el sistema de sustitución, al «principio de la voluntad y preferencia».

La salvaguardia se regula en el artículo 12.4 de la Convención:

“4. Los Estados Partes asegurarán que en todas las medidas relativas al ejercicio de la capacidad jurídica se proporcionen salvaguardias adecuadas y efectivas para impedir los abusos de conformidad con el derecho internacional en materia de derechos humanos. Esas salvaguardias asegurarán que las medidas relativas al ejercicio de la capacidad jurídica respeten los derechos, la voluntad y las preferencias de la persona, que no haya conflicto de intereses ni influencia indebida, que sean proporcionales y adaptadas a las circunstancias de la persona, que se apliquen en el plazo más corto posible y que estén sujetas a exámenes periódicos por parte de una autoridad o un órgano judicial competente, independiente e imparcial. Las salvaguardias serán proporcionales al grado en que dichas medidas afecten a los derechos e intereses de las personas"(el subrayado es nuestro).

\section{3. ¿Por qué se da la reforma?}

\subsection{Antecedentes}

Con relación a este punto, debe valorarse que nuestro ordenamiento no solo se rige por normas internas, sino que responde a tratados y convenios internacionales que, en caso versen sobre derechos humanos, tienen jerarquía constitucional, por lo que el Estado, en esos escenarios, debe reestructurar su orden interno.

Existe un conjunto de instrumentos internacionales de los que el ordenamiento peruano es tributario, como la Declaración Universal de los Derechos Humanos de 1948, la Convención sobre los Derechos del Niño de 1989, la Convención Americana sobre los Derechos Humanos de 1969 y la propia Convención Internacional de los Derechos de las Personas con Discapacidad.

Ha sido esta última, la Convención, la que ha permitido poner en contraste el cómo nuestra legislación llegó a un punto de desfase y desconoció, incluso durante más de 10 años luego de su 
ratificación en 2007, los derechos de las personas con discapacidad, pasando a promover y asegurar el goce pleno de todos sus derechos humanos, lo que conlleva al íntegro respeto de su dignidad como valor fundante de su existencia.

3.2. ¿Cómo funcionaba la actuación de las personas con discapacidad antes de la entrada en vigencia de Decreto Legislativo No 1384?

El principio general que se desprendía de la lectura del artículo $42^{6}$ del Código Civil era que, fuera de los supuestos de excepción (artículos 43 y 44), se presume que toda persona tiene plena capacidad de ejercicio, siempre que no se haya declarado su incapacidad(3:843). Como afirmaban los Mazeaud(11:300): la capacidad es la regla, mientras que la incapacidad, la excepción.

Precisamente, la declaración de incapacidad de una persona, siendo una situación excepcional, se generaba mediante una sentencia en el marco de un proceso judicial de interdicción. Marianella Ledesma indica que "la interdicción es la pretensión orientada a cuestionar el estado de incapacidad del individuo, a través de un procedimiento sumarísimo"(12:333), en el que se declaraba su incapacidad absoluta o relativa.

El artículo 45 del Código Civil establecía que "Los representantes legales de los incapaces ejercen los derechos civiles de estos, según las normas referentes a la patria potestad, tutela y curatela”. Conforme a ello, la curatela, como un mecanismo de representación legal de los "interdictos", consistía en un modelo de sustitución en la toma de decisiones para las personas que eran declaradas "interdictas". Entonces, en lugar del incapaz actuaba el curador.

Bajo dicha regulación, cualquier acto civil de administración o de disposición de los derechos de una persona "incapaz" debía ser realizado por su curador, quien, en el último escenario (actos de disposición), incluso, debía contar con una autorización judicial especial, con el de fin de tutelar el mejor interés de su representado.

Sin embargo, siguiendo un nuevo enfoque de-

${ }^{6}$ Artículo 42.- Tienen plena capacidad de ejercicio de sus derechos civiles las personas que hayan cumplido dieciocho años de edad, salvo lo dispuesto en los artículos 43 y 44 . sarrollado durante las últimas décadas en el Derecho internacional, hoy se tiende a un modelo social en la regulación de la capacidad, de integración e inclusión (democratización), partiendo del hecho de que la discapacidad no constituye una anormalidad del sujeto sino, contrario sensu, es una desadaptación de la sociedad al no tratar de manera justa y equitativa al ser humano.

En tal sentido, con la entrada en vigencia del Decreto Legislativo No 1384, que reconoce y regula la capacidad jurídica de las personas con discapacidad en igualdad de condiciones, hemos virado de un régimen de exclusión a uno de inclusión, democratizando las relaciones sociales y las jurídicas, integrando a los sujetos independientemente de su discapacidad. No se pretende sustituir la $\operatorname{voluntad}(13: 123)$, sino mantener $\mathrm{y}$, además, integrar.

Dicho sistema tiende a integrar al sujeto a la sociedad, lo que le permita interactuar en su mundo de relación de manera libre y plena, sin restricciones, obstáculos ni trabas: las barreras se eliminan en pro de la equiparación de oportunidades. A través de este nuevo sistema, se reconoce la autodeterminación y dignidad de las personas. De ese modo, la regla es que:

"Todas las personas con discapacidad tienen plena capacidad en igualdad de condiciones con los demás en todos y cada uno de los aspectos de la vida”.

Reconocer el derecho a la capacidad a todos implica, además de ello, facilitar las medidas de apoyo y salvaguardias que permitan y promuevan el ejercicio, según lo veremos con ocasión de las consultas que procedemos a absolver.

\subsection{Marco normativo}

Después de aproximadamente 4 años de la ratificación por el Perú de la Convención, el 24 de diciembre de 2012, se publicó la Ley No 29973, Ley general de la persona con discapacidad. Con ella se introducen cambios sustanciales y transversales al ordenamiento jurídico peruano. En la Segunda Disposición Complementaria Final se ordena la creación de una Comisión Revisora del Código Civil, para que, en un plazo no mayor 
de seis meses de la entrada en vigor de la Ley No 29973, revise dicho cuerpo normativo en lo referido al ejercicio de la capacidad jurídica de la persona con discapacidad y ordena la elaboración de un anteproyecto. El Reglamento correspondiente fue publicado el 7 de abril de 2014.

Luego de casi seis años de la publicación de la Ley No 29973, el 4 de setiembre de 2018, es publicado el Decreto Legislativo No 1384, Decreto Legislativo que reconoce y regula la capacidad jurídica de las personas con discapacidad en igualdad de condiciones.

Grosso modo, mediante esta reforma, se elimina la figura mediante la cual la capacidad de goce puede ser restringida por ley, y se pasa de un sistema de capacidad/incapacidad (absoluta-relativa) a uno en el cual no se niega la capacidad, sino que pasa a considerarse en sus aspectos de ser absoluta o restringida. Además, se reafirma la autonomía jurídica de las personas, su realización a través de apoyos y se deja de lado los sistemas de sustitución.

Este modelo social responde a un reconocimiento a la autonomía de la que goza la persona, entendiéndola en su dignidad como pilar de su desarrollo social, con los medios psicológicos para decidir respecto de su propia vida y el reconocimiento de la libertad que le permita tomar sus propias decisiones.

\section{Modificaciones}

El Decreto Legislativo No 1384 ha modificado el Código Civil transversalmente en casi la totalidad de sus libros; sin embargo, para efectos del presente trabajo de investigación vamos a hacer mención de las que se realizaron con ocasión del Libro de Personas.

\subsection{Sobre la capacidad jurídica}

\section{Artículo 3.- Capacidad jurídica:}

Toda persona tiene capacidad jurídica para el goce y ejercicio de sus derechos.

La capacidad de ejercicio solo puede ser restringida por ley. Las personas con discapacidad tienen capacidad de ejercicio en igualdad de condiciones en todos

\section{los aspectos de la vida.}

A lo primero que se debe hacer mención es al cambio de paradigma que se ha concluido con la presente modificación tributaria de la Convención sobre los Derechos Humanos de las Personas con Discapacidad. Así, si antes la capacidad jurídica, entendiéndola a partir de los arraigos del BGB, hacía referencia solo a la capacidad de goce(14:177), a partir de la Convención el concepto de capacidad jurídica se ha extendido y ha adoptado una naturaleza inclusiva y social.

La capacidad jurídica ya no es más, en nuestro ordenamiento - o mejor, ya no es solo-, la capacidad de goce sino que, además, ahora hace referencia a la capacidad de ejercicio. Es importante hacer esta mención pues justamente lo neurálgico de esta primera modificación, atendiendo que el antiguo artículo 3 del Código Civil expresaba que "Toda persona tiene el goce de los derechos, salvo las excepciones expresamente establecidas por ley".

Entonces, de pasar a que la regla era la presunción de que todos tenían capacidad de goce, ahora se tiene que todos ostentamos capacidad jurídica en un sentido ampliado por la Convención.

Sin embargo, nuestro Tribunal Constitucional ya ha hecho mención de lo limitado que es el concepto de la "capacidad de goce" como sinónima de capacidad jurídica. Por ejemplo, en la sentencia recaída en el Expediente No 02432-2007-HC, el Tribunal manifestó que la capacidad jurídica se expresa en dos planos: la capacidad de goce, que es el atributo de la persona para ser titular de derechos y obligaciones, y el plano de la capacidad de ejercicio, como la facultad de producir efectos jurídicos válidos para sí o para otros.

La citada modificación añade que "la capacidad de ejercicio solo puede ser restringida por ley". Respecto de esto, se debe mencionar que la capacidad de goce es inherente a la naturaleza del hombre como inherente es su libertad, de allí que no pueda ser restringida. Pero la capacidad de ejercicio puede ser limitada, sin embargo, bajo la precepción de que la regla general es que todos mantenemos una capacidad plena, las limitaciones a la capacidad deben ser señaladas por la pro- 
pia ley, la denominada incapacidad de ejercicio.

Pero hablar de limitaciones o restricciones a la capacidad, como toma la disposición normativa, es distinto a hablar de incapacidad. Hasta antes de las modificaciones en el Libro de Personas del Código Civil se tenía, por ejemplo, que los mayores de dieciséis años y menores de dieciocho eran incapaces relativos; esto ha cambiado: incapaces no son, capacidad es lo que ostentan, pero restringida. Otra muestra de que el paradigma, bajo el modelo social comentado, ha cambiado.

Por último, se ha mencionado en el presente que no es lo mismo hablar de incapacidad que de discapacidad, y es lo que ahora recoge nuestro Código a partir de la entrada en vigencia del Decreto Legislativo No 1384, y que esto responde en estricto al artículo 12 de la Convención. Sin embargo, no ha sido la Convención o el propio Tribunal Constitucional los que han adoptado o reconocido la regla del modelo social inclusivo, sino que también lo ha hecho la Corte Interamericana de Derecho Humanos, en estricto:

"La Convención Interamericana para la Eliminación de Todas las Formas de Discriminación contra las Personas con Discapacidad y en la CDPD se tiene en cuenta el modelo social para abordar la discapacidad, lo cual implica que la discapacidad no se define exclusivamente por la presencia de una deficiencia física, mental, intelectual o sensorial, sino que se interrelaciona con las barreras o limitaciones que socialmente existen para que las personas puedan ejercer sus derechos de manera efectiva"7.

En consecuencia, lo que ha pasado a hacer nuestro Código Civil es, primero, diferenciar entre discapacidad e incapacidad, pasamos de lo peyorativo a lo meramente descriptivo, y luego regular a las personas con discapacidad y capaces dentro de un marco de inclusión, protección e integración social.

\subsection{Sobre la capacidad de ejercicio plena}

Artículo 42.- Capacidad de ejercicio plena

Toda persona mayor de dieciocho años tiene plena

${ }^{7}$ Furlan y fam. Vs Argentina (2012). capacidad de ejercicio. Esto incluye a todas las personas con discapacidad, en igualdad de condiciones con las demás y en todos los aspectos de la vida, independientemente de si usan o requieren de ajustes razonables o apoyos para la manifestación de voluntad.

Excepcionalmente tienen plena capacidad de ejercicio los mayores de 14 años y menores de dieciocho años que contraigan matrimonio, o quienes ejerciten la paternidad.

La capacidad de ejercicio, como parte de la capacidad jurídica de la persona, ha sido siempre relacionada con la edad (aspecto etario).

El antiguo artículo 42 del Código Civil también lo contemplaba. La diferencia recae en que antes de la modificación quien era menor de edad era una persona incapaz relativa si era, a su vez, mayor de dieciséis ańos, e incapaz absoluto si era menor.

Como se ha mencionado, la regla ha cambiado, ahora en vez de referirse a incapaces por edad, a los menores de dieciocho años ahora se les considera como persona con capacidad restringida, no incapaces. Por otro lado, en cuanto al criterio edad, solo los menores de dieciséis años han quedado como incapaces.

Este criterio puede devenir en problemático si se analiza esta disposición con la modificación del artículo 219 del Código Civil, referido a las causales de nulidad del acto jurídico. Esta modificación consiste en que desde la vigencia del Decreto Legislativo No 1384 ya no se considera como una causal de nulidad el que el acto se haya celebrado por persona absolutamente incapaz, como lo es el menor de dieciséis años, lo que conlleva a preguntarse entonces: ¿Qué es ese acto, si no es nulo? ¿Válido y eficaz? Tengamos en cuenta que tampoco será anulable, pues así no lo refiere el también modificado artículo 221 del Código, sinsentido jurídico que deberá ser materia de interpretación favorable a la seguridad jurídica.

Por otro lado, la disposición ratifica el espíritu de la Convención, al equiparar expresamente a las personas con discapacidad con las personas que hasta antes de la modificación eran consideradas 


\section{como capaces.}

El artículo 1 de la Convención establece quiénes pueden ser considerados personas con discapacidad. Así: "[...] las personas con discapacidad incluyen a aquellas que tengan deficiencias físicas, mentales, intelectuales o sensoriales a largo plazo que, al interactuar con diversas barreras, puedan impedir su participación plena y efectiva en la sociedad, en igualdad de condiciones con los demás". Al hacer referencia a estas barreras, lo que hace la convención es reconocer que la calidad de discapacitado no es intrínseca a la persona, sino que refiere a cómo esta persona puede desenvolverse en su medio social, de ahí que la Convención adopte este modelo social.

La modificación introduce, aunque todavía sin realizar un acercamiento funcional o teórico de la institución, a la figura del apoyo y de la salvaguardia. Cabe indicar que el apoyo escapa a la figura de curador o de representante, pues la Convención ha entendido de que al ser la persona con discapacidad una persona capaz, atenta contra su dignidad humana el pretender imponerle una sustitución a su voluntad o una sustitución a sus actos. Sobre esto ahondaremos más adelante.

El nuevo artículo 42 del Código prevé, además, la capacidad plena de ejercicio en aquellas personas que, siendo incapaces absolutas o de capacidad restringida, hayan adoptado un estatus jurídico que haga presumir tal capacidad, como el caso de los mayores de 14 años y menores de dieciocho años que contraigan matrimonio, o quienes ejerciten la paternidad. Estos supuestos se suman a los considerados en el artículo 46 vigente, el que reconoce a la capacidad adquirida en caso de matrimonio o por obtención de título oficial que autorice el ejercicio de una profesión ${ }^{8}$.

\footnotetext{
${ }^{8}$ Artículo $46^{\circ}$ del Código Civil de Perú. Capacidad adquirida por matrimonio o título oficial: La incapacidad de las personas mayores de dieciséis (16) años cesa por matrimonio o por obtener título oficial que les autorice para ejercer una profesión u oficio. La capacidad adquirida por matrimonio no se pierde por la terminación de este. Tratándose de mayores de catorce (14) años cesa la incapacidad a partir del nacimiento del hijo o la hija, para realizar solamente los siguientes actos: 1 . Inscribir el nacimiento y reconocer a sus hijos e hijas. 2. Demandar por gastos de embarazo y parto. 3. Demandar y ser parte en los procesos de tenencia, alimentos y régimen de visitas a favor de sus hijos e hijas. 4. Demandar y ser parte en los procesos de filiación extramatrimonial de sus hijos e hijas. 5. Celebrar conciliaciones extrajudiciales a favor de sus hijos e hijas. 6. Solicitar su
}

Sin embargo, esta modificación también ha traído consigo, indirectamente, la derogación tácita de lo establecido en el artículo 46 del Código Civil. Lo decimos porque el artículo 42 dispone la capacidad de las personas de catorce ańos cuando ejercitan la paternidad, estableciendo para ellas una capacidad plena. Pero al observar el artículo 46 del Código, que también había sido recientemente modificado, establece la capacidad del mismo sujeto solo en cuanto algunos actos expresamente indicados.

Esta modificación ha traído como consecuencia, inevitablemente, otras dos modificaciones: las de los artículos 43 y 44, mismos que pasamos a ver en conjunto.

4.3 Sobre la incapacidad absoluta y la capacidad de ejercicio restringida

El Código Civil de 1852 solo regulaba a la incapacidad absoluta. Por su parte, el Código Civil de 1936 extendió la institución hacia la incapacidad relativa, manteniéndose esta en texto original del Código Civil del 1984. Ahora, el referido Código Civil, modificado por el Decreto Legislativo No 1384, refiere, en gran medida, a la capacidad y a la capacidad restringida, eliminando también en gran medida a la incapacidad del sujeto.

Nótese que nos cuidamos al utilizar el término "en gran medida" y "no absolutamente". Esto tiene una razón de ser: el Código no ha pasado a ser un cuerpo normativo estricto en cuanto a la capacidad, sino que ha adoptado un régimen mixto, pues no eliminó a la incapacidad, solo la redujo. Ello es así pues, en nuestro ordenamiento, todavía serán considerados incapaces absolutos, conforme el artículo, los menores de 16 años, salvo lo dispuesto por la propia ley.

Consideramos que esto último no es lo adecuado, pues se desdice del espíritu de la Convención, en tanto lo que se buscaba, justamente, era eliminar toda situación del ser humano por la que se le niegue su dignidad al momento de concebirlo como un incapaz.

Frente a la capacidad de ejercicio plena recono-

inscripción en el Registro Único de Identificación de Personas Naturales, tramitar la expedición y obtener su Documento Nacional de Identidad. 7. Impugnar judicialmente la paternidad. 


\begin{tabular}{|c|c|}
\hline Artículo 43.- Incapacidad absoluta & Artículo 44.- Capacidad de ejercicio restringida \\
\hline 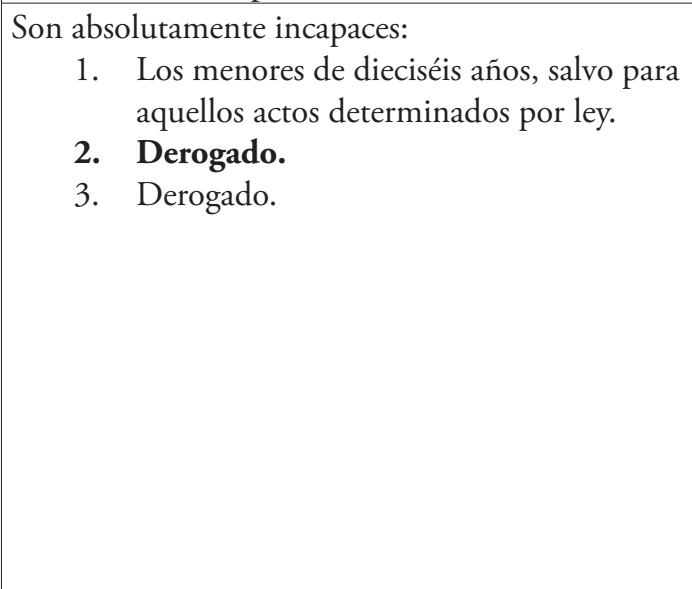 & $\begin{array}{l}\text { Tienen capacidad de ejercicio restringida: } \\
\text { 1. Los mayores de dieciséis ańos y menores de } \\
\text { dieciocho ańos de edad. } \\
\text { 2. Derogado. } \\
\text { 3. Derogado. } \\
\text { 4. Los pródigos. } \\
\text { 5. Los que incurren en mala gestión. } \\
\text { 6. Los ebrios habituales. } \\
\text { 7. Los toxicómanos. } \\
\text { 8. Los que sufren pena que lleva anexa la } \\
\text { interdicción civil. } \\
\text { 9. Las personas que se encuentren en estado de } \\
\text { coma, siempre que no hubieran designado un } \\
\text { apoyo con anterioridad. }\end{array}$ \\
\hline
\end{tabular}

cida en el artículo 42 del Código, este también pasa a regular un solo supuesto de incapacidad absoluta y lo que antes eran considerados como incapaces relativos, ahora son personas capaces, pero con una capacidad restringida en atención a su estatus en el ordenamiento.

En primer momento tenemos al artículo 43 del Cuerpo. Este artículo ya había pasado en 2008 por una modificación' que, si bien, prima facie, se considera positiva en atención a la búsqueda de no discriminación de las personas sordomudas, ciegosordos y los ciegomudos, consideramos que la derogación total de esa disposición normativa no fue coherente con la sistematicidad del código y ahora eso es palpable a raíz del nuevo inciso 9 del artículo 44 del Código.

En efecto, este nuevo inciso establece un supuesto de hecho muy específico, situación que bien hubiera podido salvarse si es que el legislador, o quien funja ese papel, hubiese modificado el citado inciso 9 del artículo 44 de la siguiente manera: "Tienen capacidad de ejercicio restringida: [...] 9. Quien no pueda expresar su voluntad de manera indubitable, siempre que no hubiera designado un apoyo con anterioridad". Nótese que se usa la fórmula adoptada por el inciso tercero derogado del artículo 43 y sin hacer mención a un tipo de persona en particular, no siendo en consecuencia discriminatorio como lo fue hasta antes de 2008.

Dejando de lado la modificación del 2008, la modificación del Decreto Legislativo No 1384 ha

${ }^{9}$ Ley No 29274 de 2008. suprimido del artículo 43 el inciso segundo, de tal manera que las personas que por cualquier causa se encuentren privados de discernimiento serán, efectivamente, capaces.

En ese contexto, la falta de discernimiento no es sinónimo de incapacidad. Esto tiene una íntima relación con la modificación del artículo 44, en tanto las personas con retardo mental o los que adolecen de deterioro mental, a pesar de ser faltas de discernimiento, no serán consideradas incapaces al haber sido derogadas como supuestos de tal artículo.

El discernimiento, a entender de Rubio Correa, es "la capacidad humana de distinguir el bien del mal [...], de desarrollar un pensamiento abstracto. Es el momento en el que el ser humano deja su ego y mundo propio y concreto para proyectarse más allá, a un mundo complejo, de muchas y variadas interrelaciones, que no solo tiene presente, sino también sentido de previsión y de futuro"(5:156). Esto responde, específicamente, al artículo 12 de la Convención y de la Ley General de la Persona con Discapacidad, en tanto disponen que la persona con discapacidad no sea considerada incapaz, interdicta y que no sea sometida en curatela conforme al reconocimiento de su dignidad.

Estas modificaciones traerán como consecuencia que las personas con retardo mental y las personas que adolezcan de deterioro mental que le impida expresar su libre voluntad no requieran nunca más de un curador, pues, bajo su potestad 
El nuevo tratamiento del régimen de la capacidad en el Código Civil peruano - Enrique Varsi, Marco Torres

\begin{tabular}{|c|c|c|}
\hline $\begin{array}{l}\text { Artículo 45.- Ajustes razonables y } \\
\text { apoyo }\end{array}$ & $\begin{array}{l}\text { Artículo 45- A.- Representantes } \\
\text { legales }\end{array}$ & $\begin{array}{l}\text { Artículo 54- B- Designación de } \\
\text { apoyos y salvaguardias }\end{array}$ \\
\hline $\begin{array}{l}\text { Toda persona con discapacidad que } \\
\text { requiera ajustes razonables o apoyo } \\
\text { para el ejercicio de su capacidad } \\
\text { jurídica puede solicitarlos o } \\
\text { designarlos de acuerdo a su libre } \\
\text { elección. }\end{array}$ & $\begin{array}{l}\text { Las personas con capacidad de } \\
\text { ejercicio restringida contempladas } \\
\text { en los numerales } 1 \text { al } 8 \text { del artículo } \\
44 \text { contarán con un representante } \\
\text { legal que ejercerá los derechos } \\
\text { según las normas referidas a la } \\
\text { patria potestad, tutela o curatela. }\end{array}$ & $\begin{array}{l}\text { Pueden designar apoyos o } \\
\text { salvaguardias: } \\
\text { 1. } \\
\text { Las personas con discapacidad } \\
\text { que manifiestan su voluntad } \\
\text { pueden contar con apoyos } \\
\text { y salvaguardias designados } \\
\text { judicial o notarialmente. } \\
\text { 2. } \\
\text { Las personas con discapacidad } \\
\text { que no pueden manifestar } \\
\text { su voluntad podrán contar } \\
\text { con apoyos y salvaguardias } \\
\text { designados judicialmente. } \\
\text { 2as personas que se } \\
\text { encuentren en estado de } \\
\text { coma que hubieran designado } \\
\text { un apoyo con anterioridad } \\
\text { mantendrán el apoyo } \\
\text { designado. } \\
\text { Las personas con capacidad } \\
\text { de ejercicio restringida } \\
\text { contempladas en el numeral } \\
9 \text { del artículo 44 contarán } \\
\text { con los apoyos y salvaguardias } \\
\text { establecidos judicialmente, } \\
\text { de conformidad con las } \\
\text { disposiciones del artículo 659- } \\
\text { E del presente Código. }\end{array}$ \\
\hline
\end{tabular}

podrán, solo si así lo hacen, nombrar a un apoyo que coadyuve a su desenvolvimiento y pueda, en su caso, servir de intérprete de su voluntad.

4.4. Sobre los ajustes razonables y el apoyo, los representantes legales y la designación de apoyos y salvaguardias

El Código Civil de 1984 propugnaba una sustitución de la persona considerada incapaz, limitaba su personalidad y vulneraba la esencia de su propia vida. Así, no consideramos errado mencionar, en analogía particular pero que no pierde certeza por lo especial de la situación de las personas con discapacidad y la regulación que debían de afrontar, que la persona que nombra un apoyo pasa a actuar como el protagonista de su propio destino jurídico; si antes no era ni un actor secundario, sino un simple telonero atrás del devenir de su propia vida, con la nueva regulación pasa a tomar las riendas de sus actos.

La modificación del artículo 45 y la incorporación de los artículos 45-A y 45-B son expresión de lo que indicamos, pues permiten a la persona con discapacidad, a su elección en caso cuente con discernimiento, nombrar a un apoyo o ajustes razonables para el ejercicio de su capacidad jurídica.

Los ajustes razonables son las modificaciones y adaptaciones necesarias y adecuadas que buscan garantizar a las personas con discapacidad el pleno goce o ejercicio en igualdad de condiciones de todos sus derechos humanos y libertades fundamentales.

El "ajuste razonable" es un término técnico, es un mecanismo que permite a la persona poder realizarse, es todo aquello que necesita para manifestar su voluntad y que se verá realizado mediante un 
apoyo que no lo limite, sino que lo coadyuve al desarrollo de su personalidad.

Por otro lado, el nuevo artículo 45-A expresa lo que expresaba el antiguo artículo 45, por el que las personas mayores de 16 años y menores de 18 años, los pródigos, los que incurren en mala gestión, los ebrios habituales, los toxicómanos y los que sufren pena que conlleve a su interdicción civil, deberán contar con un representante legal de acuerdo con las normas de la patria potestad, la tutela y la curatela.

Nótese aquí que estos casos también contravienen a lo que buscaba la Convención sobre los Derechos de las Personas con Discapacidad, pues se le impone, en caso de las personas mayores de edad, un curador que los represente y no que les sirva de apoyos. Es decir, se refuerza la regulación mixta que ha adoptado nuestro ordenamiento a partir del Decreto Legislativo No 1384.

Por otro lado, los apoyos ${ }^{10}$, conforme a lo establecido en el artículo 659-B del Código Civil, son formas de asistencia libremente elegidas por una persona mayor de edad para facilitar el ejercicio de sus derechos, incluyendo el apoyo en la comunicación, en la comprensión de los actos jurídicos y de las consecuencias de estos, y la manifestación e interpretación de la voluntad de quien requiere el apoyo.

La referida norma establece, claramente, que "El apoyo no tiene facultades de representación salvo en los casos en que ello se establezca expresamente por decisión de la persona con necesidad de apoyo o el juez en el caso del artículo 569". Es decir, en tanto las personas con discapacidad tienen plena capacidad de ejercicio, no resulta pertinente que su representante legal actúe por ellas, pues, sencillamente, no lo tienen ${ }^{11}$.

Por ello, según el vigente artículo 45 del Código Civil, "Toda persona con discapacidad que requiera ajustes razonables o apoyo para el ejerci-

\footnotetext{
${ }^{10}$ Decreto Legislativo $N^{\circ} 1384$ de 2018.

${ }^{11}$ La excepción a ello lo encontramos en el numeral 9 del Artículo $N^{\circ} 44$ del Código Civil, que regula la situación de aquella persona que se encuentra en estado de coma. Según el artículo 1976-A, [...] Las personas comprendidas en el artículo 44 numeral 9 no son responsables por las decisiones tomadas con apoyos designados judicialmente que hayan actuado con dolo o culpa.
}

cio de su capacidad jurídica puede solicitarlos o designarlos de acuerdo a su libre elección". Así, el nuevo artículo 45-B establece dos posibilidades según la persona con discapacidad cuente o no con discernimiento. Así, los escenarios son:

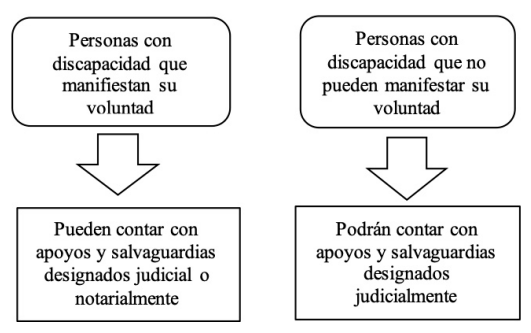

En dichos supuestos, tratándose de personas con discapacidad, distintas a las previstas en los numerales 4, 5, 6, 7 y 8 del artículo 44 del Código Civil, la persona con discapacidad, que pueda o no manifestar su voluntad, podrá directamente intervenir en la suscripción de un acto jurídico, siempre que lo haga en conjunto con su órgano de apoyo, que estará facultado para tal fin, notarial o judicialmente, según corresponda.

Cabe advertir que, el nuevo artículo 45-B del Código Civil, para efectos del acompañamiento del órgano de apoyo, utiliza una expresión potestativa (pueden o podrá); es decir, no convierte en obligatorio el acompańamiento del órgano de apoyo para la persona con discapacidad, lo cual podría resultar, en determinados casos, insuficiente para la tutela integral de la persona con discapacidad.

Adicionalmente, el incorporado artículo 1976-A del Código Civil establece que "La persona que cuenta con apoyos es responsable por sus decisiones, incluso de aquellas realizadas con dicho apoyo, teniendo derecho a repetir contra él. Las personas comprendidas en el artículo 44 numeral 9 no son responsables por las decisiones tomadas con apoyos designados judicialmente que hayan actuado con dolo o culpa".

Como se puede advertir, la referida norma establece que la persona con discapacidad, que pueda o no manifestar su voluntad, será responsable por las decisiones que pudiera adoptar en el marco de un proceso de transacción, siempre que se en- 
cuentre debidamente acompañado por su órgano de apoyo, quien velará por que la persona con discapacidad pueda comprender los actos jurídicos y sus consecuencias.

Naturalmente, en caso que el órgano de apoyo, valiéndose de su cercanía y confianza respecto de la persona con discapacidad, le perjudicara con la suscripción de determinados actos jurídicos, obteniendo indebidamente un lucro para sí o un tercero, en perjuicio de la persona con discapacidad, aquél podrá repetir contra el órgano de apoyo por los daños y perjuicios generados.

Nótese que se reconoce un derecho de repetición en favor de la persona con discapacidad, en contra de su órgano de apoyo; sin embargo, aquella — como regla general — no podrá pretender absolutamente nada al tercero con el que se vincula.

Naturalmente, ello constituye un escenario excepcional, pues, en principio, insistimos, el único responsable de las decisiones es la propia persona con discapacidad, por lo que aquellos actos jurídicos en los que él intervenga, contando con su órgano de apoyo, resultará válido y plenamente eficaz.

Finalmente, el nuevo artículo 45-B establece que las personas que se encuentren en estado de coma, como indica el numeral 9 del artículo 44, contarán con apoyos designados judicialmente, conforme lo que indica el nuevo artículo 659-E, que expresa que el juez puede determinar, de modo excepcional, los apoyos necesarios para las personas con discapacidad que no puedan manifestar su voluntad y para aquellas con capacidad de ejercicio restringida.

\section{Conclusiones}

Luego del análisis realizado, hemos arribado a las siguientes conclusiones:

La capacidad jurídica ya no solo es referente de la capacidad de goce, como indicaba la academia, arraigada a la influencia de códigos decimonónicos. Ahora, acorde con la Convención, la capacidad jurídica se ha ampliado a la capacidad de goce como a la capacidad de ejercicio.

A partir de la entrada en vigencia del Decreto Le- gislativo No 1384, Decreto que reconoce y regula la capacidad jurídica de las personas con discapacidad en igualdad de condiciones, se ha consolidado la regulación de un modelo social en torno al tratamiento de los derechos de las personas con discapacidad, lo que implica que aquellas tienen plena capacidad de ejercicio.

El modelo social vigente ha reemplazado un régimen de sustitución de la voluntad de las personas incapaces por uno de asistencia, a través de los denominados apoyos, quienes no son representantes legales de las personas con discapacidad. Así, como regla general, tenemos que la persona que cuenta con apoyos es responsable por sus decisiones, incluso de aquellas realizadas con dicho apoyo.

Las modificaciones realizadas al Código Civil, si bien buscan contribuir con un mayor alcance a la tutela de la dignidad de las personas, no han sido ajenas a algunos desfases legislativos, como el que el ordenamiento no responde plenamente a la Convención, sino que establece un régimen mixto en el que se convive todavía con la figura del incapaz y del interdicto.

\section{Agradecimientos}

El presente artículo es resultado de parte del proyecto de investigación "Tratado de Derechos reales. Garantías. Tomo IV", financiado por el Instituto de Investigación Científica de la Universidad de Lima.

Esta investigación ha tenido la valiosa colaboración de Piero Cortina Gonzales y Brenda Nadeshda Ventosilla Portocarrero, estudiantes de Derecho de la Universidad Nacional Mayor de San Marcos y asistentes del curso de Derechos Reales y Derechos de las Personas, respectivamente, en la misma Casa de Estudios, y Mariana Aguilar Ávila, estudiante de Derecho y asistente de investigación en el Instituto de Investigación Científica de la misma Universidad de Lima. 


\section{Referencias}

1. Goldstein M. Diccionario jurídico: Consultor Magno. Buenos Aires: Cadiex International S.A.; 2010.

2. Tobías J. Elementos del Derecho civil. Buenos Aires: Editorial Astrea; 1991.

3. Varsi E. Tratado de Derecho de las personas. Lima: Gaceta Jurídica; 2014.

4. $\quad$ Espinoza J. Derecho de las personas: concebido y personas naturales. Lima: Grijley; 2016.

5. Rubio M. El ser humano como persona natural. Lima: Fondo Editorial de la Pontificia Universidad Católica del Perú; 1992.

6. Aparicio ML. Evolución de la conceptualización de la discapacidad y de las condiciones de vida proyectadas para las personas en esta situación. En Consejero S, Reyes M, (edits.). El largo camino hacia una educación inclusiva: la educación especial y social del siglo XIX a nuestros días. Pamplona; XV Coloquio de Historia de la Educación; 2009: 130-131.

7. Asociación Americana sobre Retraso Mental. Retraso Mental: definición, clasificación y sistemas de apoyo. Madrid: Alianza Editorial; 2002.

8. Palacios A. El modelo social de discapacidad: orígenes, caracterización y plasmación en la Convención Internacional sobre los derechos de las Personas con discapacidad. Madrid: Editorial Cinsa; 2008.

9. Verdugo M. Análisis de la definición de discapacidad intelectual de la Asociación Americana sobre retraso mental de 2002; 2003. Disponible en: http://inico.usal.es/publicaciones/pdf/AAMR_2002.pdf. Fecha de consulta: 30 de octubre de 2018.

10. Bach M. El derecho a la capacidad jurídica en la Convención de la ONU sobre los derechos de las personas con discapacidad: conceptos fundamentales y lineamientos para una reforma legislativa. En Bariffi F, Palacios A, (edits.). Capacidad jurídica, discapacidad y derechos humanos: una visión desde la Convención Internacional sobre los Derechos de las Personas con Discapacidad. Buenos Aires: Ediar; 2011: 55-107.

11. Mazeaud H, Mazeaud J. Lecciones de Derecho civil, Tomo I (trad. Luis Adorno). Buenos Aires: Zavalía editor; 1959.

12. Ledesma M. Comentarios al Código Procesal Civil, Tomo II. Lima: Gaceta Jurídica; 2011.

13. Roca O. La capacidad de las personas naturales: Análisis del Código Civil a la luz de la Ley General de Discapacidad: Cambio de visión del Derecho Civil por los Derechos humanos. Revista del Instituto de Familia de la Universidad Femenina del Sagrado Corazón 2015; 04: 113-137.

14. Torres A. Introducción al Derecho. Lima: Editorial Idemsa; 2011.

\section{Normas citadas}

Ley N²9274 (24/12/2008), Ley que modifica el artículo 46 del Código Civil referido a la capacidad adquirida por matrimonio o título oficial.

Código Civil de Perú (24/07/1984).

Decreto Legislativo $\mathrm{N}^{\circ} 1384$ (04/08/2018).

\section{Jurisprudencia citada}

Furlan y fam. vs Argentina (2012): Corte IDH, 31 de agosto de 2012 (parr.133).

Recibido: 30 de mayo de 2019

Aceptado: 5 de agosto de 2019 